\title{
Managing the Public Sector in Kenya: Reform and Transformation for Improved Performance
}

\author{
Kempe Ronald Hope, Sr. \\ Development Practice International \\ PO Box 30002, Oakville, ON L6H 7L8, Canada \\ E-mail: hopekr@dpiintl.ca
}

Received:November 23, 2012 Accepted:December 02, 2012 DOI:10.5296/jpag.v2i4.2751

\begin{abstract}
Public sector reform remains a necessary and on-going policy objective for many developing countries. In Kenya, this is being done to overhaul its administrative system to better serve the needs of both government and the citizenry with improved delivery of public services to reduce poverty, improve livelihoods, and sustain good governance. Although the first attempts at the reform and transformation of the public sector in Kenya began in 1965, it was not until the early 1990s that serious efforts were made toward the reform and transformation of the country's public sector management. This work analytically examines and reviews the public sector reform and transformation efforts in Kenya to improve public sector performance and overall public service delivery.
\end{abstract}

Keywords: Kenya, public sector management, public sector reform, public sector transformation, performance management 
1. Introduction

This work analytically examines and reviews the public sector reform and transformation efforts in Kenya to improve public sector performance and overall public service delivery. Effective public sector management is a critical ingredient for sustainable development in Africa. Consequently, public sector reform remains a necessary and on-going policy objective for such countries as Kenya. This is being done to overhaul administrative systems to better serve the needs of both government and the citizenry with improved delivery of public services to reduce poverty, improve livelihoods, and sustain good governance. Although the first attempts at the reform and transformation of the public sector in Kenya began in 1965 (OPM/PSTD, 2010), it was not until the early 1990s that serious efforts were made toward the reform and transformation of the country's public sector management.

Like other African countries, these efforts in Kenya have been driven primarily by the fact that the state bureaucracy in the country has been underperforming and public service delivery has not been serving the public interest within its most optimal capability. The reforms in Kenya evolved and culminated in the notion of re-engineering of the public sector in the context of public sector transformation, drawing on elements of what came to be known in the literature and practice as the "New Public Management" (NPM). This NPM broad term symbolizes the aim of fostering a performance-oriented culture that seeks to revamp the process through which public organizations operate in order to increase efficiency, effectiveness, and encompassing client-oriented, mission-driven, and quality-enhanced management. It is intended to better serve the needs of both government and the citizenry with improved delivery of public services to reduce poverty, improve livelihoods, and sustain good governance (Hope, 2001).

The NPM movement is driven to maximize productive and allocative efficiencies that are hampered by public agencies that are unresponsive to the demands of citizens and led by bureaucrats with the power and incentives to expand their administrative empires (Hope, 2002). In addition, the NPM makes a rigid formal separation between policy-making and service delivery. It is used to describe a management culture that emphasizes the centrality of the citizen or customer, as well as accountability for results. Moreover, the concept is centered on the proposition that a distinct activity - management, as opposed to administration - can be applied to the public sector, as it has been applied to the private sector, and it includes a number of elements:

- An emphasis on efficiency in the services provided directly by the public sector;

- A movement away from input controls, rules, and procedures toward output measurement and performance targets;

- The devolution of management control with improved reporting and monitoring mechanisms;

- The flexibility explore alternatives to direct public provision and regulation that might yield more cost-effective policy outcomes; 
and

- The strengthening of strategic capacities to guide the transformation of the state and allow it to respond to external changes and diverse interests automatically, flexibly, and at least cost.

\section{Public Sector Reform and Transformation: Analytical Review and Assessment}

The government of Kenya currently "regards [its] public sector transformation strategy as a dynamic and focused process designed to fundamentally reshape the Public Service to accomplish its role in the achievement of Vision 2030" (Isahakia, 2010: 5). This transformation strategy is also seen as representing a transition for the public service and the beginning of a more cohesive, long-term approach to reform (Isahakia, 2010). The efforts to create an efficient government and engender a culture of performance and quality service delivery across the entire Kenyan public sector has a lengthy history, beginning as early as 1965 when the government set forth an institutional framework for reform through its Sessional Paper No. 10 (OPM/PSTD, 2010).

However, although the Kenyan civil service operated effectively since that time, and was seen as one of the best in sub-Saharan Africa, it began declining around the end of the 1970s (World Bank, 2001). The "problems that developed in tandem with expansion included excessive employment with attendant overstaffing, and declining productivity, service levels, pay, morale, discipline and ethics" (World Bank, 2001: 2). Oyugi (2006: 41) has further observed that "by the late 1970s the situation had gone out of control" quoting the then Head of the Civil Service who lamented that "the problem of indiscipline in the Service was such that it posed a challenge to the future of the Service". This state of affairs was attributed to the fact that, over time, the powers and responsibilities of the statutory appointing and disciplinary institutions had been eroded and usurped by powerful forces with influential connections to the apex of power.

Several decades later, beginning in 1993, the government returned to a specific focus on public sector reform and transformation. Those efforts, since then to date, can be classified into four periods (Hope, 2012). The first period either covers the years 1993-97 according to World Bank (2001); 1993-98 according to Republic of Kenya (2008) and Marwa and Zairi (2009); or 1993-2000 according to Oyugi (2006). From this author's perspective it covered the years 1993-98. Nonetheless, this period evolved when the government launched the Civil Service Reform Program (CSRP) I in 1993 to enhance public service efficiency and productivity. The focus was on cost containment (OPM/PSTD, 2010), and the program was influenced largely by the fiscal need to reduce the size of the mainstream civil service (World Bank, 2001). Implementation was driven through a Steering Committee at the national, provincial and district levels and in each Ministry with a national Secretariat as its operational arm (Marwa and Zairi, 2009).

There were five broad policy areas examined under the CSRP I:

- Civil Service Organization - The streamlining of organizational structure to 
reflect better defined ministerial and departmental functions, including clear definition and specification of the internal functions of ministries and departments, clear hierarchy of authority and span of control, and more accurate job descriptions.

- Staffing Levels - Including downsizing of the service; establishment of appropriate staffing levels for all cadres in the service; and improving staffing control mechanisms through computerization of the establishment and improvement of the payroll system.

- Pay and Benefits - The achievement of compensation levels that were geared towards attracting and retaining professional and managerial talent in a competitive market economy as well as monetization of allowances.

- Personnel Management and Training - Including the rationalization of personnel management policies; identification of inadequacies in the existing personnel planning and vacancy management; improvement of disciplinary systems; promotion; and capacity development.

- Financial and Performance Management - Including transparency and accountability in financial management; institutionalization of control systems including computerization; management of the national budget; clear standards against which performance can be accurately measured; perfection of performance evaluation instruments; and use of performance evaluation to impinge upon personnel replacement, training, discipline and rewards for enhanced productivity (Nzioka, 1998).

The Deputy Director of the CSRP Secretariat at the time (see Nzioka, 1998) noted that there were some achievements recorded under the CSRP I. They included: (1) the success of the Voluntary Early Retirement Scheme (VERS) with the government attaining its target number of retirees; (2) the abolition of more than 26,000 posts in addition to the freezing of posts that fell vacant due to the VERS; (3) the development of an Integrated Payroll and Personnel Database (IPPD) system; (4) decompression of pay scales; (5) development of a training policy; and (6) design and introduction of unique identification numbers for civil servants to assist in the improvement of establishment control and maintenance of payroll integrity including elimination of ghost workers.

However, despite these achievements, many of the activities in this CSRP I did not contribute significantly to the improvement of wider public sector performance. This was so because they were not anchored in a coherent strategy for reforming the role of government writ large. For example, the World Bank (2001: 3) observed that:

Although the initial civil service retrenchment exercise proceeded quickly, its cost containment objectives were rapidly contradicted and frustrated by the awarding of a huge pay rise to the Teachers' Service and the politically motivated hiring of a large number of additional teachers in the run-up to the 1997 elections. 
In addition, Oyugi (2006) noted that the CSRP I was, more or less, a stand-alone initiative that was not integrated with budgetary reforms and generally did not have the required impact of a downward push on the government wage bill while, at the same time, the quality of public service delivery deteriorated. Moreover, a number of lessons learned were identified by Nzioka (1998) with the key ones being the following:

- The need for adequate planning before implementation of any reform to, among other things, prioritize activities and allocate adequate time and resources for implementation.

- Training and capacity development are of vital importance for the success of any reform initiative. If civil servants are not prepared, for example, to respond to the demands of a rapidly changing socio-economic environment, then the result can be a loss of momentum for reform activities.

- The need to adopt new technologies, especially information technologies, which are necessary for timely and accurate decision-making.

- The importance and need to build acceptance of reform initiatives particularly among top managers in the service.

Building on the experience gained and lessons learned under the CSRP I, the government reformulated and reconfigured the CSRP and outlined the strategies for a CSRP II. Towards the end of 1999, the government announced a comprehensive and integrated public sector reform program to tackle the challenges facing the entire public sector. The CSRP II was focused on performance improvement and there were plans for a CSRP III whose focus was to be on consolidating and sustaining the gains made (OPM/PSTD, 2010; OP/PSRDS, 2005). The CSRP II spanned the years 1999-2002 and was the second period of public sector reform and transformation.

The priority reform areas under the CSRP II were identified as:

- Rationalization of Ministerial Functions and Structures - The undertaking of a comprehensive assessment of ministerial functions including identifying overlapping and duplicating functions as well as functions that can be commercialized, contracted-out and privatized; reviewing of organizational structures; determination of optimal staffing levels; and the updating of job descriptions, re-grading of posts and introduction of a new performance appraisal system.

- Staff Rationalization and Management of the Wage Bill - Improvement of the design and implementation of the VERS; developing an overall structure for establishment and payroll; developing and implementing a new IPPD system; and a ban on recruitment except in critical and essential services.

- Pay and Benefits Reforms - Including increasing the housing allowance for all civil servants and teachers; enhancement of salaries and allowances for civil servants and the security forces; undertaking a comprehensive job evaluation and 
re-grading exercise; establishment of a Permanent Public Service Remuneration Review Board (PPSRRB) to address, among other things, salaries and benefits for all public servants in a holistic and rationalized manner; and implementing a pilot program on a performance-related pay system,

- Performance Improvement Initiatives - Including formulation of a strategy for performance improvement in the public service; introduction of results-based management $(\mathrm{RBM})$ in the public service to shape organizations and work activities for the achievement of pre-determined outputs/results and re-orientate the goals and objectives of the workforce towards cost-effectiveness and responsiveness to customer demands and needs; and developing a modern performance appraisal system.

- Training and Capacity Building - Undertaking a training needs assessment to determine the existing performance gaps in terms of the skills requirements; addressing issues of succession management in the public service; retraining of civil servants to cope with the increased job demands and improve operational flexibility by extending the range of skills through multi-skilling; and strengthening the Kenya Institute of Administration (KIA) in providing high quality market-oriented training courses to current civil servants and retirees (OP/PSRDS, 2005; World Bank, 2001; Oyugi, 2006).

The foregoing areas were established by the government to be the priority areas for CSRP II. However, there were a number of additional areas that were also pursued. They included development and implementation of a Medium-Term Expenditure Framework; strengthening of government finance and accounting functions; and legal and judicial reform (World Bank, 2001).

The CSRP II was deemed to have suffered the same fate as the CSRP I to the extent that it failed to arrest declining public confidence in public sector management standards and conduct or deteriorating public satisfaction with government services (OPM/PSTD, 2010). In fact, the World Bank rated the overall performance of both the CSRP I and CSRP II as unsatisfactory. This outcome rating was derived from the Bank's finding that both its own role and that of the government implementation performance were unsatisfactory (World Bank, 2001).

A number of exogenous and endogenous factors have been determined to have affected the implementation and outcome of the CSRP II. With respect to the exogenous factors (those outside the control of government), the main argument here seems to have been that the economy was weak due to bad weather which affected productivity and, hence, government revenues. That, in turn, influenced government spending decisions, or became an excuse for such, including not accessing already available World Bank credit for the CSRP. This was reflected in long delays in the processing of payments and a slow public procurement process. Processing time was 25 days longer than usual (World Bank, 2001).

In terms of the endogenous factors, the main ones were: (1) there was little indication of 
government's commitment to consistent and steady reform processes and this was reflected in the slow rate of implementation of reform activities; (2) the implementing agency, the Directorate of Personnel Management (DPM), under which the CSRP Secretariat fell, lacked the necessary clout and political backing to implement the reforms; (3) reform activities lacked proper sequencing and many were added, some at the behest of donors it must be noted, without proper planning; and (4) there was a lack of ownership (World Bank, 2001; Oyugi, 2006). This last point on ownership is of major significance for successful outcomes of programs geared toward public sector reform which also encompass capacity development. Hope (2011), for example, has pointed out that local ownership with control is a key principle for achieving results in reform programs. It must be a local endogenous process to better reflect local priorities and interests and avoid being donor-driven or imposed.

In December 2002, a new government was elected on a platform of reforms and, among other things, committed itself to do business differently. This was Kenya's first transfer of power through elections since independence, and this newly elected government wanted to quickly exhibit its reformist credentials and stamp them on the nation. With the country facing challenges that required urgent attention, the government announced its socio-economic blueprint in 2003, entitled Economic Recovery Strategy for Wealth and Employment Creation 2003-2007 (ERS 2003-2007). The ERS 2003-2007 also kick-started the new government's public sector reform efforts which covered the years 2003-07 and was Kenya's third period of public sector reform and transformation.

The ERS 2003-2007 had, as a fundamental pillar, the strengthening of institutions of governance, It noted that "the Government is convinced that good governance underpins sustainable development" (Republic of Kenya, 2003: ix). In that regard, the ERS 2003-2007 outlined various reforms in, among others, public administration, further noting that:

Improving public administration is essential to economic recovery. The sector is excessively large thereby absorbing inordinately large amount of national resources. The sector is also characterized by wastefulness and inefficiency. Consequently, the sector has become a bottleneck to the overall development of Kenya (Republic of Kenya, 2003: 11).

Furthermore, the ERS 2003-2007 announced that "the government is committed to accelerating the Public Service Reform to create a leaner, efficient, motivated and more productive Public Service that concentrates public finance and human resources on the delivery of core government services" (Republic of Kenya, 2003: 11). The reforms were to also focus on providing adequate incentives to attract and retain skilled personnel to achieve a pay structure and size of the civil service consistent with both macroeconomic objectives and a sustainable wage bill. The key elements of this civil service reform strategy and activities, and which were envisaged for implementation by June 2004, included the following:

- Accelerating the on-going ministerial rationalization and developing strategic plans for ministries/departments in order to allow proper utilization of resources on clearly identified core functions, determination of appropriate staffing levels, objective appraisal of staff, and better and improved methods of supervising staff based on achievement of set targets, among others; 
- Developing, introducing and institutionalizing performance-based management practices in the public service;

- Undertaking job evaluation to form a basis for determining a rational grading structure and terms of service for civil servants;

- Undertaking service delivery surveys in all ministries/departments and developing and installing service charters with clear service benchmarks and standards in order to enhance efficiency, transparency and accountability in service delivery;

- Developing a clear recruitment and training policy aimed at ensuring proper supply and development of skills in the civil service and pegging promotion on both performance and training; and

- Putting all Permanent Secretaries and Chief Executives of parastatals on performance contracts (PCs) (Republic of Kenya, 2003).

Concerned with the slow pace of implementation of its reform initiatives, the government took a Cabinet decision in September 2004 to formally prescribe results-based management $(\mathrm{RBM})$ as its strategy for changing the culture and modus operandi of the public sector (OPM/PSTD, 2010). RBM is a program approach to management that integrates strategy, people, resources, processes, and measurements to improve decision-making, transparency, and accountability (CIDA, 2009). It focuses on achieving outcomes, implementing performance measurement, learning, adapting to change, as well as reporting performance. It is not a management tool, but rather a way of working that looks beyond activities, processes, and outputs to focus on actual results - the outcomes of RBM projects and programs.

To operationalize the RBM strategy, a rapid results approach was adapted by the government as a structured methodology for building and practicing RBM, This led to the introduction of a rapid results initiative (RRI). The RRI was introduced to cultivate a strong focus on results and was used to attempt to fast track improvements in service delivery and/or working conditions by several public sector institutions. According to OPM/PSTD (2010: 3), "many RRIs succeeded in delivering tangible results to citizens and helped consolidate support for reform". It was further deemed that some of the building blocks for institutionalizing and mainstreaming RBM had been put in place. They included strategic planning, performance contracting, annual work plans, and service delivery charters (OPM/PSTD, 2010).

The political negotiations that resulted from the violence in 2008, that followed the elections in December 2007, eventually led to the formation of a Grand Coalition Government (a government of national unity) and also the establishment of the Office of the Prime Minister (OPM). The OPM shall cease to exist following the first general elections which will eventually follow the promulgation of the 2010 constitution. These political developments formed an important part of the context of reforms in the public sector in the fourth period of public sector reform and transformation covering the years 2008 to present. In 2008, the government released its Medium Term Plan 2008-2012 (MTP 2008-2012). The MTP 2008-2012, and its update to 2013, are the first of the successive medium-term plans being 
used to outline policies, reform measures, projects, and programs that the government is committed to implementing in support of the Kenya Vision 2030. The Kenya Vision 2030 is the country's development blueprint, covering the period 2008 to 2030. An efficient, motivated and well-trained public service is one of the major foundations of that Vision with public service reforms further enhancing, among other things, performance contracting (Republic of Kenya, 2007), to build capacity in governance and inculcate public service values and ethics for national transformation (Republic of Kenya, 2008, 2010a). The MTP 2008-2012, and its update to 2013, both recognize that an effective and efficient public sector is essential to achieving the Kenya Vision 2030 by creating an enabling environment for the private sector as the engine of growth for the country's economy. Transparency, accountability, participation and the rule of law are to constitute an integral part of the reform agenda (Republic of Kenya, 2008, 2011).

With the establishment of the OPM, the Prime Minister, as per the National Accord and Reconciliation Act, 2008, was mandated to coordinate and supervise the execution of the affairs and functions of the government including Ministries. The OPM also published a Strategic Plan in 2009 covering the period 2009-12 (OPM, 2009). This Strategic Plan brought to life the constitutional mandate of the Prime Minister and set out the goals of the OPM. In it, the Prime Minister noted that:

Citizens expect the government to provide quality and timely services at all times. Demand for improved government performance has grown recently and we must listen and be responsive. Although the e-Government, Performance Contracting and Rapid Results Initiatives have led to significant improvements, more remains to be done. Therefore, this Plan will give priority to improving service delivery by accelerating existing initiatives and extending them across all public services. We will work with Ministries to identify the next wave of initiatives and we will coordinate implementation of service improvement initiatives by Ministries, Departments and Agencies of Government (Odinga, 2009: vii).

The Prime Minister further said:

The strategic objectives for the plan period are to: improve service delivery; build strong capacity for policy development and coordination; create a new culture of setting priorities; focus government on effective delivery of policies and priorities; and steer Public Service Reform as an enabler of good policy and delivery. This plan is thus about working towards giving Kenyans the Kenya they want - a prosperous, democratic, equitable and modern nation (Odinga, 2009: vii).

Consequently, there was a shift in emphasis from the narrow civil service to the broader public sector and, in order to drive the public sector reforms, a Public Service (Sector) Transformation Department (PSTD) was created by separating and absorbing the public sector reform functions of the Department of Public Sector Reform and Performance Contracting. The PSTD was charged with two principal responsibilities:

(1) To lead the transformation of the public service (including the revised strategy for public sector reform) so as to strengthen and build the capacity of the public service; 
(2) To improve delivery of services to citizens (OPM, 2009).

To engage the public sector reform agenda, as envisaged in the OPM Strategic Plan, the PSTD embarked on the preparation of a public sector transformation strategy which it officially released in January 2010 with the title Public Sector Transformation Strategy: From Reform to Transformation 2010-14 (PSTS) (OPM/PSTD, 2010). This PSTS established a broad policy framework to guide the introduction and implementation of new policies and legislation aimed at making the public sector work better (Isahakia, 2010). It defines transformation in the public service as "a fundamental and sustainable change that meets citizen needs and aspirations" (OPM/PSTD, 2010: 8). It further regards the public sector as having three attributes. First, engagement with and services to the citizens of Kenya should engender trust and be based on respect. Second, the machinery of government should function smoothly in a coordinated and efficient manner to respond to the needs of Kenyans and to achieve shared goals without organizational barriers and selfish interests compromising common purpose. Third, every ministry, department and agency in the public sector is to be goal-driven and have the systems, tools, organizational culture and management practices in place to deliver demonstrable benefit to the citizens of Kenya now and in the future (OPM/PSTD, 2010).

The PSTS is comprised of three components: (1) Service and Openness; (2) Coordination and Cooperation; and (3) Effectiveness and Accountability. The first component is intended to transform delivery of public sector services and engagement with citizens. This means that services are: (a) available to those who need them; (b) easily accessible; (c) relatively affordable and of acceptable quality; and (d) provide adequate information to assist in decision-making. The intended outcomes are: (1) citizens' satisfaction with government service delivery; (2) citizens' confidence in government communications; and (3) mutually respectful and sustainable public sector stakeholder partnerships. It is about the type of image the public sector presents to Kenyans. Moving from being closed and secretive, insensitive and self-interested, risk-averse and preoccupied with protecting of turf, to being open, respectful, and responsive to the needs of the public (OPM/PSTD, 2010).

The second component seeks to strengthen capacity across the whole of government to coordinate and cooperate on policy development and program delivery. Its focus is on crossing institutional boundaries and working collectively to foster an enabling environment that supports public sector institutions to deliver. It also entails making a concerted effort to ensure that government institutions are not operating as islands disconnected from each other but rather that government is working as one joined-up or linked-up entity. The envisioned outcomes are: (1) institutionalized, sequenced and systematic approach to government policy, planning, budgeting and delivery that is directly linked to the Kenya Vision 2030 and other national development priorities - a clear line of sight from national priorities to all government program policies and implementation; (2) synergy in government functions and operations - to increase both the perception and the reality that the government is working together in a cohesive manner by strengthening the frameworks, systems and approaches of government that transcend organizational boundaries resulting in one government that speaks with one voice; and (3) fit for purpose government institutional arrangements and structures - 
enhancing effectiveness and efficiency of government sectors and institutions by strengthening coordination structures and mechanisms, mobilizing resources, building capacity, developing partnerships with public sector stakeholders, and developing mechanisms for joint reclassification of sectors (OPM/PSTD, 2010).

The third and final component focuses on enabling government institutions to conduct their ongoing program business in a goal-driven manner, which means to plan, allocate resources, deliver, monitor, and report on the contribution they make in the lives of Kenyans. This means developing government institutions and ensuring that each of them is efficiently, effectively and ethically able to fulfill its mandate, The sought after outcomes are: (1) programs and priorities of institutions are aligned to the Kenya Vision 2030 and other national development goals; (2) improved capacity to manage for results by creating an enabling internal environment for RBM in each public sector institution, and the embedded practice of RBM in the normal business activities of each organization; and (3) achievement of high standards of public management by enabling public sector institutions to ensure that their standards of public management conform to established government-wide and generally accepted international standards (OPM/PSTD, 2010).

To implement the PSTS, a work plan, results framework, and governance framework have been developed. In addition, a number of cross-cutting issues with potentially significant impacts on outcomes have been identified. They include gender mainstreaming, youth mainstreaming, the challenge of HIV/AIDS, environmental management, drug and alcohol abuse, and public sector governance. The OPM, through its PSTD, oversees implementation of the PSTS and, particularly, the institutionalization of RBM which requires various and different initiatives from institutions. The PSTD provides the leadership and coordination to the implementation and monitoring of the reform initiatives. Its primary mission is to drive forward the implementation agenda for transforming the public service, improving the quality and responsiveness of public services and promoting a strong and professionally well-managed public sector, capable of enabling and facilitating the achievement of the Kenya Vision 2030 (OPM/PSTD, 2010).

Implementation of the PSTS therefore rests with the public sector institutions. Transformation is not regarded nor seen as the sole responsibility of one central agency but rather as the accountability of every public sector organization and to be undertaken directly by them, with the OPM, through the PSTD, providing technical support and partnership for realizing results. A monitoring and evaluation framework is being used to track progress. It will evaluate the extent to which the PSTS targets and outcomes are being accomplished and will also assist in the identification of corrective measures in a timely manner. The results framework - with its outcomes, indicators, and outcome measures - is to play a significant role in the monitoring and evaluation process (OPM/PSTD, 2010).

In August 2010, Kenyans also overwhelmingly approved a new constitution. That constitution contains various principles and elements that will have both direct and indirect impacts on public sector performance, reform, and transformation ad infinitum. For example, Article 47 in Part 2 of the Bill of Rights states, among other things, that "Every person has 
the right to administrative action that is expeditious, efficient, lawful, reasonable and procedurally fair". In Chapter 6 of the 2010 constitution on "Leadership and Integrity", it sets out a framework of leadership and integrity as it pertains to officers of the State. Furthermore, the 2010 constitution, in Article 232, lays out values and principles of public service which apply to public service in both levels of government and all State corporations as well (Republic of Kenya, 2010b).

All of these principles and elements in the 2010 constitution are also consistent with, and related to, the components of the PSTS and this foundation augurs well for a much more successful effort at public sector reform, this time around, compared to the past. There is now a supreme, lawful, and legally binding basis for Kenyan public servants and their institutions to modify their behavior in delivering public services and interacting with their fellow Kenyans in that pursuit. Both the 2010 constitution and the PSTS are anchored in the view that efficiently and effectively delivered public services are not a privilege in a democratic environment. In fact, they are a legitimate expectation of Kenyans.

Reforming and transforming the public sector for improved delivery of public services means redressing the imbalances of the past by focusing on meeting the needs of all Kenyans. Improving service delivery also calls for a shift away from inward-looking, over-centralized, hierarchical and rule-bound bureaucratic systems, processes and attitudes, that currently permeate the Kenya public service, and a search for new ways of working which put the needs of the public first, is better, faster, and more responsive to the citizens' needs. It also means a complete change in the manner that services are delivered. The objectives of service delivery must therefore include not only equity but also efficiency as was recognized by the government of South Africa, for example, in its public sector transformation strategy (Republic of South Africa, 1997).

It must also be noted here that the introduction of a public sector reform and transformation program cannot be achieved in isolation from other fundamental management changes within the public sector. It must therefore be part of a fundamental shift of culture whereby public servants see themselves first and foremost as servants of the people of Kenya and where the public service is managed with service to the public as its primary goal. Public sector reform and transformation is also a dynamic process out of which a completely new relationship is developed between the public service institutions and the public (Republic of South Africa, 1997). To successfully implement a public sector reform and transformation program also requires the use of new management tools such as performance contracting, for example (Hope, 2012).

Performance contracting in the public sector has been in place in Kenya since 2004 and the process was revamped in 2011 when a Policy Steering Committee on Performance Management was established by the government and given overall responsibility for the management and coordination of performance management in the three arms of government, including oversight of the implementation of reforms in the performance contracting system. Performance contracts represent a state-of-the-art tool for improving public sector performance. In fact, they are now considered important instruments for enhancing good 
governance and accountability for results in the public sector.

In Kenya, performance contracts are freely negotiated agreements between the government and the management of a public entity. It is a freely negotiated performance agreement between the Government, acting as the owner of a public agency, and the management of the agency. The performance contract specifies the mutual performance obligations, intentions and responsibilities of the two parties. Each performance contract quite clearly specifies the intentions, obligations, as well as responsibilities and powers of the contracting parties (OPM/PCD, 2010). It also addresses economic, social and other tasks to be undertaken for economic or other desired gain. "It is therefore a [performance] management tool for ensuring accountability for results by public officials, because it measures the extent to which they achieve targeted results" (OPM/PSRPC, nd: 1) and, as the maxim says, "If you cannot measure, you cannot control, if you cannot control, you cannot manage, if you cannot manage, you cannot deliver".

The expected outcomes of the use of PCs in Kenya include:

- Improved efficiency in service delivery to the public by ensuring that holders of public office are held accountable for results;

- Improvement in performance and efficiency in resource utilization and ensuring that public resources are focused on attainment of the key national policy priorities;

- Institutionalization of a performance-oriented culture in the Public Service;

- Ability to measure and evaluate performance;

- Ability to link reward for work to measurable performance;

- Instilling accountability for results at all levels in the government;

- Ensuring that the culture of accountability pervades all levels of government;

- Reduction or elimination of reliance on Exchequer funding by public agencies;

- Ability to strategize the management of public resources; and

- Recreating a culture of results-oriented management in the Public Service (OPM/PCD, 2011).

\section{Conclusion}

Kenya has been undertaking public sector reform and transformation since the mid-1960s. This suggests the country has taken cognizance of both the need for such on-going reforms 
and transformation as necessary and essential to bring about governance improvements that are needed for sustainable poverty reduction and development, and the application of current best practice in public sector reform and transformation for a performance-oriented public service culture. Public sector reform and transformation are means to an end. It is a means towards achieving higher-order development goals - particularly growth, poverty reduction, peace, and stability - through better public management and improved public service delivery. Consequently, developing countries, such as Kenya, must endeavor to undertake and implement public sector reform and transformation as necessary.

Performance measurement can be the first step toward improving the performance of public sector institutions, and, when backed by an appropriate incentive system, it can also help shift organizational focus from inputs to outputs and outcomes and, consequently, improve efficiency and effectiveness (Schiavo-Campo and Sundaram, 2001). Introducing a stronger performance orientation in Kenya's public sector is very important for improving the performance of the country's public sector institutions. While performance can be regarded as complex because it also entails a subjective dimension, in terms of results, it is important for the Kenyan authorities not to neglect entirely the subjective effort but recognize it in appropriate ways. However, performance should be measured primarily in terms of results as both the research literature and development practice demonstrates.

\section{References}

CIDA (Canadian International Development Agency) (2009), "Results-based Management". Available at: http://www.acdi-cida.gc.ca/acdi-cida/ACDI-CIDA.nsf/eng/NIC-31595014-KEF [Accessed 12 December 2010].

Hope, K. R. (2001), "The New Public Management: Context and Practice in Africa", International Public Management Journal, 4(2), pp. 119-34.

Hope, K. R. (2002), “The New Public Management: A Perspective from Africa”, In K. McLaughlin, S. R. Osborne, and E. Ferlie (eds.), New Public Management: Current Trends and Prospects. London: Routledge, pp. 210-26.

Hope, K. R. (2008), Poverty, Livelihoods, and Governance in Africa: Fulfilling the Development Promise. New York: Palgrave Macmillan.

Hope, K. R. (2011). "Investing in Capacity Development: Towards an Implementation Framework", Policy Studies, 32(1), pp. 59-72.

Hope, K. R. (2012), The Political Economy of Development in Kenya. New York: Continuum Books.

Isahakia, M. (2010), "Preface", In OPM/PSTD (Office of the Prime Minister/Public Sector Transformation Department), Public Sector Transformation Strategy: From Reform to Transformation 2010-14. Nairobi: OPM/PSTD, pp. 5-6.

Marwa, S. M. and Zairi, M. (2009), "In Pursuit of Performance-Oriented Civil Service Reforms (CSRs): A Kenyan Perspective”, Measuring Business Excellence, 13(2), pp. 34-43. 
Nzioka, G. (1998), “Kenya”, In. K. Kiragu (ed.), Civil Service Reform in Southern \& Eastern Africa: Lessons of Experience. Available at:

http://www.utumishi.go.tz/index2.php?option=com_docman\&task=doc_view\&gid=59\&Itemi $\mathrm{d}=57$ [Accessed 12 December 2010].

Odinga, R. A. (2009), "Foreword” to Strategic Plan 2009-2012. Nairobi: OPM, pp. vii-viii.

Odinga, R. A. (2010a), "Foreword" to Report on Evaluation of the Performance of Public Agencies for the Financial Year 2008/2009. Nairobi: OPM/PCD (Office of the Prime Minister, Performance Contracting Department), pp. v-vii.

Odinga, R. A. (2010b), "Foreword" to Public Sector Transformation Strategy: From Reform to Transformation 2010-14. Nairobi: OPM/PSTD (Office of the Prime Minister, Public Sector Transformation Department), p. 4.

OP/PSRDS (Office of the President/Public Service Reform and Development Secretariat) (2005), "Donor/GOK Consultative Meeting: Report". Available at: http://siteresources.worldbank.org/INTKENYA/Resources/psrd_sec_rpt.pdf [Accessed 11 December 2010].

OPM (Office of the Prime Minister) (2009), Strategic Plan 2009-2012. Nairobi: OPM.

OPM/PCD (Office of the Prime Minister, Performance Contracting Department (2010), Report on Evaluation of the Performance of Public Agencies for the Financial Year 2008/2009. Nairobi: OPM/PCD.

OPM/PCD (2011) Report on Evaluation of the Performance of Public Agencies for the Financial Year 2009/2010. Nairobi: OPM/PCD.

OPM/PSRPC (Office of the Prime Minister, Public Sector Reforms and Performance Contracting) (nd), "What is a Performance Contract". Available at: http://www.psrpc.go.ke [Accessed 12 May 2010].

OPM/PSTD (Office of the Prime Minister, Public Sector Transformation Department) (2010), Public Sector Transformation Strategy: From Reform to Transformation 2010-14. Nairobi: OPM/PSTD.

Oyugi, W. O. (2006), "Public Service Reform in Kenya: Lessons of Experience", In K. Kiragu and G. Mutahaba (eds.), Public Service Reform in Eastern and Southern Africa: Issues and Challenges. Dar es Salaam: Mkuki na Nyota Publishers, pp. 3-65.

Republic of Kenya (2003), Kenya: Economic Recovery Strategy for Wealth and Employment Creation 2003-2007. Nairobi: Ministry of Planning and National Development.

Republic of Kenya (2007), Kenya Vision 2030: A Globally Competitive and Prosperous Kenya. Nairobi: Republic of Kenya.

Republic of Kenya (2008), Kenya Vision 2030: First Medium-term Plan (2008-2012). 
Nairobi: Republic of Kenya.

Republic of Kenya (2010a), First Annual Progress Report on the Implementation of the First Medium-term Plan (2008-2012) of Kenya Vision 2030. Nairobi: Republic of Kenya.

Republic of Kenya (2010b), The Constitution of Kenya, 2010. Nairobi: Republic of Kenya.

Republic of Kenya (2011), Kenya Vision 2030: First Medium Term Plan Update. Nairobi: Republic of Kenya.

Republic of South Africa (1997), Batho Pele - "People First": White Paper on Transforming Public Service Delivery. Available at:

http://www.dpsa.gov.za/documents/acts\&regulations/frameworks/white-papers/transform.pdf [Accessed 12 December 2010).

Schiavo-Campo, S. and Sundaram, P. S. A. (2001), To Serve and to Preserve: Improving Public Administration in a Competitive World. Manila: Asian Development Bank.

World Bank (2001), Implementation Completion Report on a Credit in the Amount of SDRs 17.2 Million to the Government of the Republic of Kenya for an Institutional Development and Civil Service Reform Project. Washington, DC: World Bank.

\section{Copyright Disclaimer}

Copyright reserved by the author(s).

This article is an open-access article distributed under the terms and conditions of the Creative Commons Attribution license (http://creativecommons.org/licenses/by/3.0/). 